\title{
RARE ANTHROPOGENIC AND NATURAL PARTICLES SUSPENDED IN DEEP OCEAN WATERS
}

\author{
JACQUES JEDWAB
}

Laboratoire de Géochimie, Université Libre de Bruxelles, 50, Avenue Roosevelt, B-1050 Brussels (Belgium)

Received January 8,1979

Revised version received April 16, 1979

\begin{abstract}
Four hundred membrane filters from the Atlantic and Pacific deep waters have been scanned for coloured and opaque particles by a method integrating the light and the scanning electron microscopes, the electron microprobe and the micro-X-ray diffraction camera. About 40 different types of particles have been found. A tentative classification of the particles and of their morphological and chemical varieties is presented, according to their anthropogenic or natural origins. From this point of view, the particles fall into five groups: (1) particle species exclusively produced by man's activities (like brass, cobalt aluminate); (2) particles exclusively produced by natural processes (like amphibole, ilmenite); (3) particles rarely produced by natural processes, but massively so by man (like metallic copper, chromium oxide); (4) a large group of particles massively produced by nature and by man (like magnetite spherules, malachite); (5) a very small group of particles whose origin could not be attributed at present. Very few entirely new compounds from the point of view of continental mineralogy have been encountered.
\end{abstract}

\section{Introduction}

It has rarely been attempted to investigate directly which particles are brought to the oceans by human activities and to estimate their contribution to the suspended solid load of the deep ocean waters. Most of what we know stems from isotopic, radioactive and trace element data obtained on bulk samples, and from calculated enrichment factors. These data shed no direct light on the speciation of the elements, including the heavy metals, and consequently, on their anthropogenic or natural origin.

One of the early objectives of GEOSECS [1] was to assess the reality and the extent of man's inputs to the oceans [2]. Under the GEOSECS program, for the first time an extensive collection of first rate samples of marine particulate matter uniformly filtered and with due precautions taken against in situ, on-board and laboratory contamination has been made available [3].

GEOSECS Publication No. 126.

\section{Experimental principles and methods}

What principles and methods are available to distinguish possible anthropogenic particles? A prelimin. ary review of inorganic particles emitted by globally significant sources, like metal smelting, welding and machining, fossil fuel burning, cement fabrication and handling, etc., had shown that the products of these sources fall into four broad optical categories [4] (of which examples are given):

(1) Opaque particles of high to low reflectivity (welding spherules, soot, metal flakes).

(2) Transparent, colourless compounds of high refractive index (pigmentary titanium oxide).

(3) Transparent, coloured compounds of high to medium refractive index (iron hydroxide, copper and brass patina).

(4) Transparent, colourless compounds of medium to low refractive index (fly ash, concrete dust).

From a practical point of view, and according to the experience of our laboratory, it appeared that the first three groups could easily be distinguished by an experienced optical microscopist, whereas the last 
one could easily be overlooked for lack of prominent features. It was thus decided to concentrate on the opaque, coloured and highly refracting particles. Despite the fact that the optical microscope is an excellent means to sort out particles, it is inadequate to yield the chemical data necessary to identify unknown particles in samples in which a priori almost anything could be found.

We had previously developed a method in our laboratory by which particles collected on membrane filters can be selected visually under the light microscope (LM), equipped with transmitted, reflected and polarized light and oil-immersion objectives (5). The selected individual particles may be subsequently relocated and analyzed under the scanning electron microscope (SEM) equipped with an electron microprobe attachment (EMP), and their structure eventually determined with a micro-X-ray diffraction camera. Integration of the optical, morphological, chemical and structural data, and their comparison with the published data can generally yield an unambiguous identification. This method, which had been devised for lunar and cosmic particles, was easily adaptable to the oceanic problem and to the Nuclepore filters used in the GEOSECS expeditions with few changes.

During preliminary studies on a series of filters from the HARMATT AN cruise ("Jean-Charcot" cruise HLT-71, sponsored by the French Centre National de la Recherche Scientifique (CNRS)), it had been observed that our method has two more advantages, when looking for rare species among oceanic particles:

(1) Most of the particles, overwhelmingly composed of opal (diatoms and diatom debris), calcium carbonate (coccoliths and coccolith debris), lightelement silicates (clay, felspar, quartz) disappear from sight under oil immersion, since they are transparent, colourless and low to medium refracting.

(2) In contrast, the coloured, or high-refracting, or opaque particles are visually enhanced, so that extremely rare particles, even when present at the $10^{-6}$ or $10^{-7}$ concentration level, are easily caught by the eye.

On the other hand, it has been our experience that LM and SEM pictures of the same fields appear extremely different, since the abundant, transparent particles reappear under the SEM. This is extremely troublesome, and makes re-finding of the particles selected under the LM impossible. One thus needs a very precise device to mark the selected particles under the LM down to the $1 \mu \mathrm{m}$ scale, if one wants to take advantage simultaneously of the sorting abilities of the LM and the morphological and analytical abilities of the SEM-EMP. This need has been fulfilled by the development of a high-precision object marker [6]. It imprints a straight line symmetrical on both sides of a visually selected particle fixed on the filter (Figs. 1 and 2). This line can later easily be found again under the SEM, whatever the tilt angle of the filter, and the particle precisely located, no matter how crowded around it is by transparent particles.

\section{Results}

Using this method, we have scanned about 400 filters provided by the GEOSECS, CNRS and Woods Hole Oceanographic Institution cruises. A list of studied stations, number of filters, and a discussion of the possible contamination problems is found in a previous paper devoted to the $\mathrm{Cu}-\mathrm{Zn}-\mathrm{Pb}$ minerals which have been discovered mainly in the North Atlantic [7].

This search was primarily aimed at the optically obvious or distinctive particles, among which it was thought that the anthropogenic contributions could be found and recognized most easily. During the course of the study, less distinctive particles were found by chance: elementary sulfur, zinc carbonate and zinc hydroxychloride. Barite, which is present as very small and indistinguishable particles [8] has been found by purely EMP mapping techniques. These finds suggest that some more colourless species must exist in seawater, and that our findings are certainly not closed.

A summary of all rare particle species found to date is given in Table 1, along with descriptive and chemical data, and references pertaining to their determination and to their previously observed occurrences in natural and industrial environments. This list is obviously not a determinative scheme, which will be published later. Definite mineral names have been given to the compounds for which an X-ray diffraction film was obtained which matched the reflections of a candidate with compatible optical and 


\section{TABLE 1}

Types of particles found in deep ocean waters

Chemical or descriptive name Mineralogical name Chemical composition

Diagnostic features and references (major and minor elements) or formula

Metals, alloys and elements

iron

$\mathrm{Fe}$

Stainless steel

Metallic copper

Copper zinc alloy

Metallic aluminum

Elementary sulfur

Sulfides

Iron sulfide

Zinc sulfide

Copper sulfide

Oxides and hydroxides

Red iron oxide

Black iron oxide

Iron titanium oxide

Titanium oxide (hematite)

$\mathrm{Fe}_{2} \mathrm{O}_{3}$

brass

$\mathrm{Cu}, \mathrm{Zn}(\mathrm{Sn}, \mathrm{S})$

aluminum

Al

sulfur

S

(pyrite or $\quad \mathrm{FeS}_{2}$

marcassite)

(sphalerite)

$\mathrm{ZnS}$

(covellite)

$\mathrm{Cu}_{2} \mathrm{~S}$

(magnetite) $\quad \mathrm{Fe}_{3} \mathrm{O}_{4}$

(ilmenite) $\quad \mathrm{FeTiO}_{3}$

(rutile)

$\mathrm{TiO}_{2, \text { tetragonal }}$ jagged flakes, highly reflecting in white $[4,10,11]$

jagged flakes, highly reflecting in white $[4,12]$

jagged flakes, highly reflecting in copper-red; sometimes altered to (para)tenorite and/or malachite $[4,7,10-12]$

jagged flakes, highly reflecting in gold-yellow; sometimes altered to (para)tenorite and/or malachite $[4,7,12]$

jagged flakes, highly reflecting in white $[4,12]$

crystals [13,14] (fig. 3)

octahedra; polycrystalline aggregate [10,13-16]

isotropic fragments, transparent in dark brown, with high optical relief $[4,10-12,14]$

opaque, highly reflecting and anisotropic sulfur-rich patches on tenorite $[10,11,14,17,18]$

spheres, fragments, hexagonal platelets (fig. 4), transparent in deep-red; sized micro-crystals mixed with other pigments (fig. 9) $[4,10-12,14]$

opaque spheres (fig. 5), octahedra, fragments of low reflectivity $[4,10-12$, $14,19,20$ ]

semi-transparent to opaque fragments of low reflectivity $[10,11]$

transparent prisms (fig. 6) and broken fragments of high optical relief; spheroidal micro-crystals, weakly transparent in dark brown (fig. 7) and highly reflecting in white, frequently clustered $[4,10-12,21]$ 
Table 1 (continued)

\begin{tabular}{|c|c|c|c|}
\hline Chemical or descriptive name & Mineralogical name & $\begin{array}{l}\text { Chemical composition } \\
\text { (major and minor elements) } \\
\text { or formula }\end{array}$ & Diagnostic features and references \\
\hline Copper oxide & $\begin{array}{l}* \text { tenorite and } \\
\text { paratenorite }\end{array}$ & $\begin{array}{l}\mathrm{CuO}_{\text {monocl. and }} \\
\mathrm{CuO}_{\text {tetragonal }}\end{array}$ & $\begin{array}{l}\text { flakes, transparent in dark brown } \\
\text { (tenorite); black spheres (paratenorite); } \\
\text { as aiterations of copper and brass }[7,10 \text {, } \\
11,14]\end{array}$ \\
\hline Chromium oxide & (eskolaite) & $\mathrm{Cr}_{2} \mathrm{O}_{3}$ & $\begin{array}{l}\text { spheroidal, sized micro-crystals, weakly } \\
\text { transparent in dark brown, brightiy } \\
\text { reflecting in vivid green, often cluster- } \\
\text { ed }[10-12] \text { (Fig. } 8 \text { ) }\end{array}$ \\
\hline Cobalt aluminate & cobalt blue & $\mathrm{CoAl}_{2} \mathrm{O}_{4}$ & $\begin{array}{l}\text { fragments, transparent and reflecting } \\
\text { in bright blue [12] }\end{array}$ \\
\hline Antimony oxide & (valentinite) & $\mathrm{Sb}_{2} \mathrm{O}_{3}$ & $\begin{array}{l}\text { transparent, colourless crystals mixed } \\
\text { to other pigments }[12,13] \text { (Fig. 9) }\end{array}$ \\
\hline Iron hydroxide & (goethite) & $\begin{array}{l}\mathrm{FeO} \cdot \mathrm{OH}(\mathrm{Al}, \mathrm{Si}, \mathrm{S}, \mathrm{Cl}, \mathrm{Ca}, \mathrm{Ti}, \mathrm{Cr} \\
\mathrm{Mn}, \mathrm{Ni}, \mathrm{Cu}, \mathrm{Zn}, \mathrm{Pb})\end{array}$ & $\begin{array}{l}\text { flakes, pellets, fragments (Fig. } 10 \text { ), } \\
\text { aggregates of micro-crystals, spherules, } \\
\text { transparent in light yellow to dark } \\
\text { brown }[4,10,11,22,23]\end{array}$ \\
\hline
\end{tabular}

\section{Sulfates}

Barium sulfate (barite) $\mathrm{BaSO}_{4}(\mathrm{Sr})$

Strontium sulfate (celestite) $\mathrm{SrSO}_{4}(\mathrm{Ba})$

Carbonates and hydroxycarbonates

$\mathrm{Cu}_{2}\left(\mathrm{CO}_{3}\right)(\mathrm{OH})_{2}(\mathrm{Zn}, \mathrm{Cl}, \mathrm{Pb})$

\begin{tabular}{|c|c|c|}
\hline $\begin{array}{l}\text { Copper zinc hydroxy- } \\
\text { carbonate }\end{array}$ & $\begin{array}{l}\text { (malachite/ } \\
\text { rosasite) }\end{array}$ & $(\mathrm{Cu}, \mathrm{Zn})_{2}\left(\mathrm{CO}_{3}\right)(\mathrm{OH})_{2}(\mathrm{Cl}, \mathrm{Pb})$ \\
\hline Lead (hydroxy) carbonate & $\begin{array}{l}\text { (cerussite or } \\
\text { hydroxycerussite) }\end{array}$ & $\begin{array}{l}\mathrm{PbCO}_{3} \text { or } \mathrm{Pb}_{3}\left(\mathrm{CO}_{3}\right)(\mathrm{OH})_{2} \\
(\mathrm{Cu}, \mathrm{Zn})\end{array}$ \\
\hline Zinc(hydroxy)carbonate & $\begin{array}{l}\text { (smithsonite or } \\
\text { hydrozincite) }\end{array}$ & $\mathrm{ZnCO}_{3}$ or $\mathrm{Zn}_{5}\left(\mathrm{CO}_{3}\right)_{2}(\mathrm{OH})_{6}$ \\
\hline Iron magnesium carbonate & (mesitine) & $(\mathrm{Fe}, \mathrm{Mg}) \mathrm{CO}_{3}$ \\
\hline Cerium lanthanum fluo- & (bastnaesite) & $(\mathrm{Ce}, \mathrm{La}) \mathrm{CO}_{3} \cdot \mathrm{F}$ \\
\hline
\end{tabular}

transparent, colourless crystals, pellets, fragments, spheroids of medium refractivity $[4,8,12,13]$

same $[8,13,24] ;$ Acantharia spines and fragments $[8]$

pale green to emerald green flakes, crystals, pellets, fragments, incrustations (Fig. 11); alteration of copper and brass $[7,13,25-27]$

malachite-looking particles with high amounts of $\mathrm{Zn}[7,13]$

Laurionite-looking particles devoid of chlorine $[7,13,25,28]$

colourless, medium refracting flakes $[7,13,25]$

transparent, greenish fragments [13]

yellow crystal of high refractivity [13]

carbonate

\section{Hydroxychlorides}

Copper hydroxychloride

(atacamite or paratacamite)

$\mathrm{Cu}_{2} \mathrm{Cl}(\mathrm{OH})_{3, \text { orth. or }} \mathrm{Cu}_{2} \mathrm{Cl}(\mathrm{OH})_{3, \text { trig, }}$ $(\mathrm{Zn}, \mathrm{Pb})$

malachite-looking particles containing high amounts of chlorine $[7,13,25,27]$

Lead hydroxychloride

$\mathrm{Pb}(\mathrm{OH}) \mathrm{Cl}_{\text {orth. }}(\mathrm{Cu}, \mathrm{Zn})$ crystals, fragments, needles, polycrystaline aggregates, incrustations (Fig. 12) transparent in dark brown, highly reflecting with pearly haze $[7,13,25,28]$ 
TABLE 1 (continued)

\begin{tabular}{|c|c|c|c|}
\hline Chemical or descriptive name & Mineralogical name & $\begin{array}{l}\text { Chemical composition } \\
\text { (major and minot elements) } \\
\text { or formula }\end{array}$ & Diagnostic features and references \\
\hline Zinc hydroxychloride & - & several compounds & $\begin{array}{l}\text { polycrystalline aggregates (Fig. 13) and } \\
\text { decaying crystals (Fig. 14) [25] }\end{array}$ \\
\hline \multicolumn{4}{|l|}{ Silicates } \\
\hline $\begin{array}{l}\text { Calcium iron alumino- } \\
\text { silicate }\end{array}$ & $\begin{array}{l}\text { (pyroxene or } \\
\text { amphibole) }\end{array}$ & $\mathrm{Ca}, \mathrm{Al}, \mathrm{Fe}, \mathrm{Si}, \mathrm{Mg}(\mathrm{Ti}, \mathrm{Mn})$ & $\begin{array}{l}\text { Green, transparent shards and fragments } \\
{[29,30]}\end{array}$ \\
\hline $\begin{array}{l}\text { Sodium aluminum sulfo- } \\
\text { silicate }\end{array}$ & (ultramarine) & $\mathrm{Na}_{6} \mathrm{Al}_{6} \mathrm{Si}_{6} \mathrm{O}_{24} \mathrm{~S}_{2}$ & $\begin{array}{l}\text { fragments transparent in bright blue, } \\
\text { of low reflectivity }[12,29]\end{array}$ \\
\hline Glass spheres & (fly ash) & $\mathrm{Ca}, \mathrm{Al}, \mathrm{Fe}, \mathrm{Si}(\mathrm{Ti})$ & $\begin{array}{l}\text { colourless spheres with gas bubbles } \\
{[4,19]}\end{array}$ \\
\hline \multicolumn{4}{|l|}{ Carbonaceous particles } \\
\hline Iron vanadium carbide & - & $\mathrm{Fe}, \mathrm{V}(\mathrm{S})$ & opaque fragments of low reflectivity \\
\hline Coal & coal & $(\mathrm{Fe}, \mathrm{S}, \mathrm{Cl}, \mathrm{Ca}, \mathrm{Al}, \mathrm{Si})$ & $\begin{array}{l}\text { transparent to opaque fragments of } \\
\text { low reflectivity with cell remains }[4]\end{array}$ \\
\hline Coenospheres & - & $(\mathrm{Fe}, \mathrm{S}, \mathrm{Cl}, \mathrm{Ni}, \mathrm{V})$ & $\begin{array}{l}\text { hollow, opaque spheres, reflecting in } \\
\text { bronze-brown and anisotropic }[4,31]\end{array}$ \\
\hline Black sausages & (automobile soot) & $(\mathrm{Fe}, \mathrm{S}, \mathrm{Cl}, \mathrm{Cr}, \mathrm{V}, \mathrm{Ni}, \mathrm{Cu}, \mathrm{Zn}, \mathrm{Br}, \mathrm{Pb})$ & $\begin{array}{l}\text { elongated bodies of agglomerated, sized } \\
\text { spheroids, opaque and reflecting in } \\
\text { brown-black [4] (Figs. 15, 16, } 17 \text { and } \\
\text { 18) }\end{array}$ \\
\hline White sausages & (fecal pellets) & (Al, Si, S, Cl, Ca, Ti, Fé, Zn) & $\begin{array}{l}\text { elongated bodies, transparent in } \\
\text { amber-yellow, with numerous included } \\
\text { and ad sorbed micro-particles (Figs. 19, } \\
20,21 \text {, and 22). }\end{array}$ \\
\hline Brown spheres & (algae?) & $(\mathrm{Al}, \mathrm{Si}, \mathrm{S}, \mathrm{Cl}, \mathrm{K}, \mathrm{Ca}, \mathrm{Ti}, \mathrm{Fe}, \mathrm{Ni}, \mathrm{Cu}, \mathrm{Zn})$ & $\begin{array}{l}\text { spheroidal particles, transparent in } \\
\text { light to dark brown, containing opaque } \\
\text { inclusions, and very weakly reflecting; } \\
\text { isolated or clustered [ } 32 \text { ] (Figs. } 21 \text {, } \\
23 \text { and } 24 \text { ) }\end{array}$ \\
\hline
\end{tabular}

* Definite determinations.

chemical data $[9-11]$. These definitely determined minerals are marked with an asterisk.

One ventured to give mineral names (between brackets) to the compounds which presented a set of optical, morphological and chemical properties sufficiently definite to suggest a provisional, yet sound, solution. The decision to classify a compound as oxide, hydroxide or carbonate has been made after considering the optical and morphological properties, as well as the positive and negative chemical data, since oxygen ànd carbon are not detected by our EMP. Let us take the difficult case of cerussite/hydrocerussite as an example.

We observed some particles which looked like laurionite but which contained neither chlorine, silicon, nor phosphorus. It could either be a carbonate or hydroxycarbonate, an oxide or hydroxide, but also a sulfate or hydroxysulfate, since energy dispersive spectrometers are unable to separate sulfur from lead at $2.3 \mathrm{keV}$. One had thus to rely on optical 
data to make the final decision. These data exclude immediately the oxides, since the four known lead oxides (litharge, massicot, plattnerite and minium) are respectively red, yellow, black and red, and have high refractive indices. Lead hydroxides are entirely unknown from the continental mineralogy. Fortunately, like laurionite, our mineral presented a pearly haze when observed at high magnification under reflected, polarized light. The lead sulfate, anglesite, does not display that haze.

Such determinations may look flimsy to the continental mineralogist, but they are proposed here as challenges to go farther.

Organic compounds were named according to their optical and morphological properties. Nicknames have been used for very definite recurrent compounds for which nomenclature is still in a preliminary state.

The filters studied were mainly from the Atlantic Ocean, but about 100 Pacific filters have been scanned, mostly from the central South Pacific (GEOSECS stations 257, 263, 269, 310). No striking difference was observed between the Atlantic and the Pacific particle types, except for one orange compound, possibly organic, in the Pacific. The descriptions are thus largely valid for both oceans.

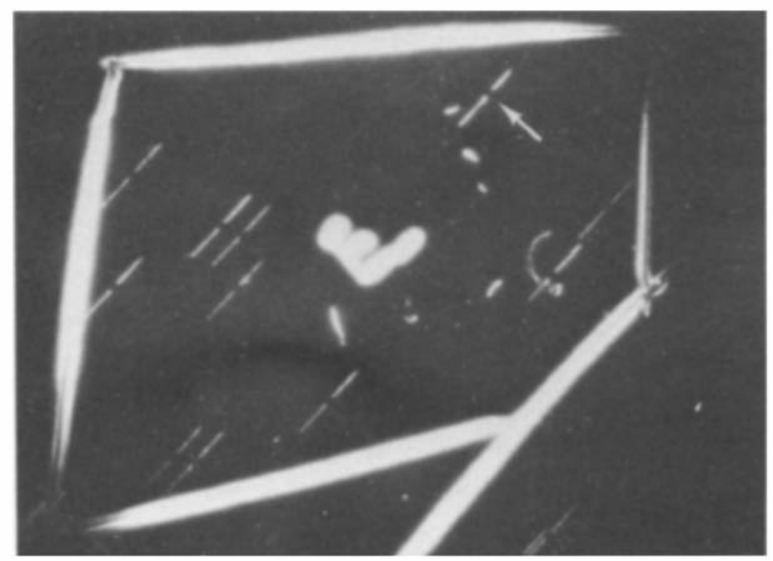

Fig. 1. Portion of filter after marking 11 particles. Small interrupted lines: traces of object marker in the filter. Arrow: place of particle E19 displayed in Fig. 2. Large white lines: outline cut with a lancet before stripping the filter portion from the glass slide and bringing it under the SEM/EMP. Station 2111 ATLANTIS II 85-2 cruise (= GEOSECS station 120), $2195 \mathrm{~m}$ (LM. Transm. Pol. Width of picture $=9 \mathrm{~mm}$.)

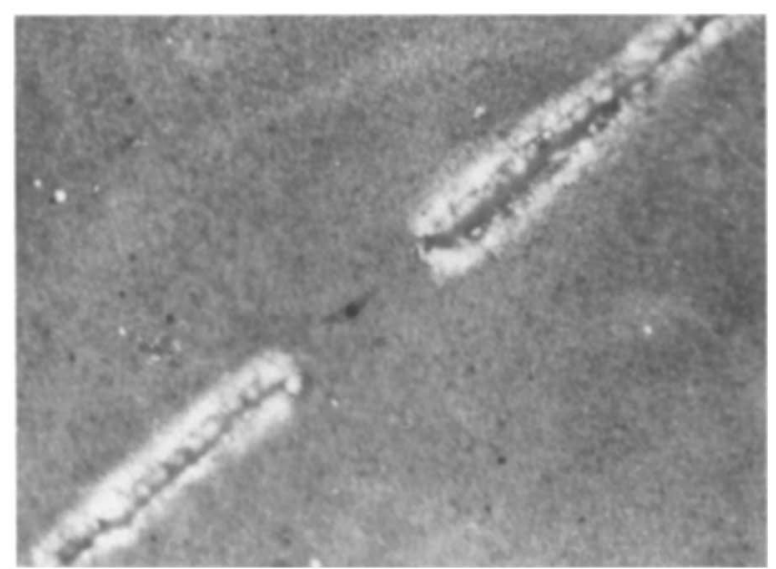

Fig. 2. Object between marks. Object E19; station 2111, $2195 \mathrm{~m}$. (LM. Transm. Pol. Width of picture $=615 \mu \mathrm{m}$.)

A few comments, which could not be fitted in Table 1 are given here.

Iron and stainless steel flakes. Ferrous particles never occur on the filters as machined particles (turnings), which would have indicated a nearby source (shop contamination), or a very recent input. Rust is never observed on the particles, indicating either a very rapid alteration, or the preservation of a part of the metallic iron injected in the oceans by some passivation mechanisms.

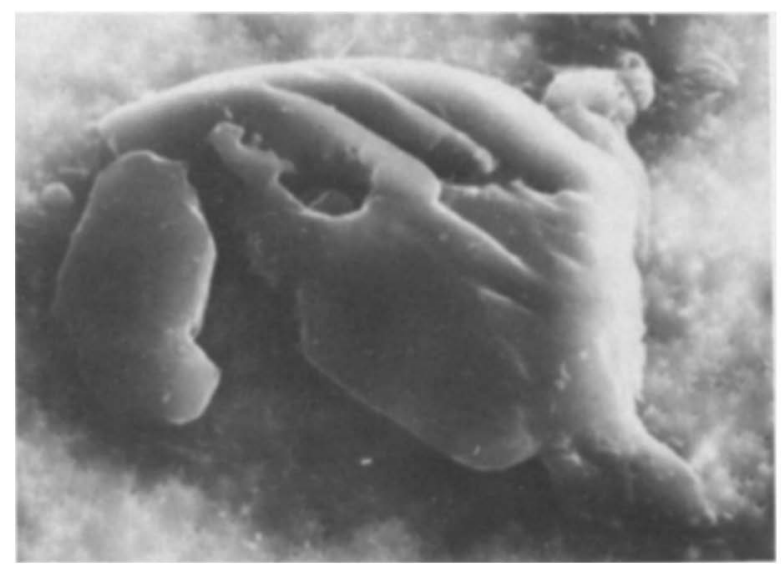

Fig. 3. Crystallized sulfur. Station 2111,954 m. (SEM. Sec. mode. Width of picture $=80 \mu \mathrm{m}$.) 


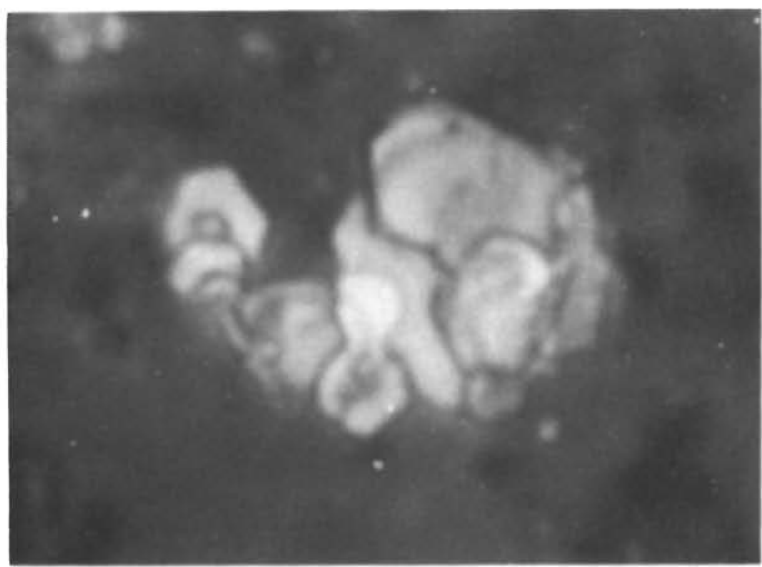

Fig. 4. Cluster of hexagonal hematite platelets. Object 7; station $2111,3199 \mathrm{~m}$. (LM. Refl. Width of picture $=10 \mu \mathrm{m}$.)

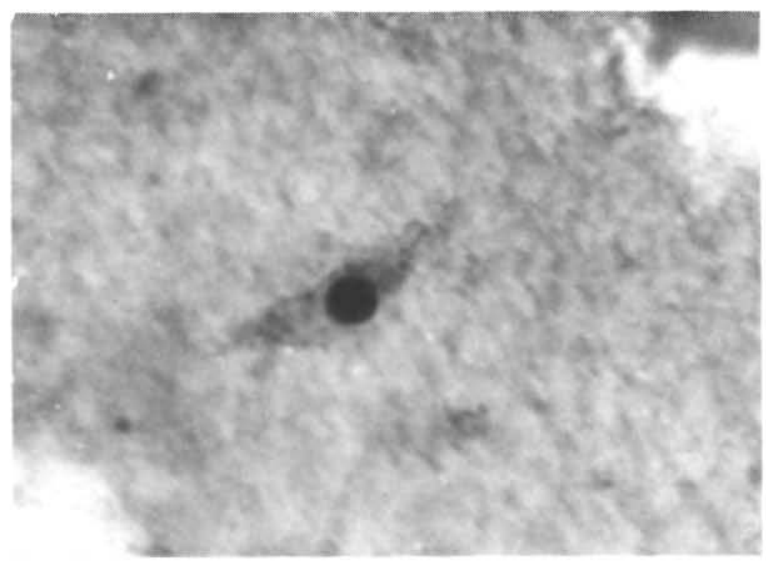

Fig. 5. Magnetite spherule. Same object as in Fig. 2. Black magnetite spherule included in a white sausage. (LM. Transm. Width of picture $=160 \mu \mathrm{m}$.)

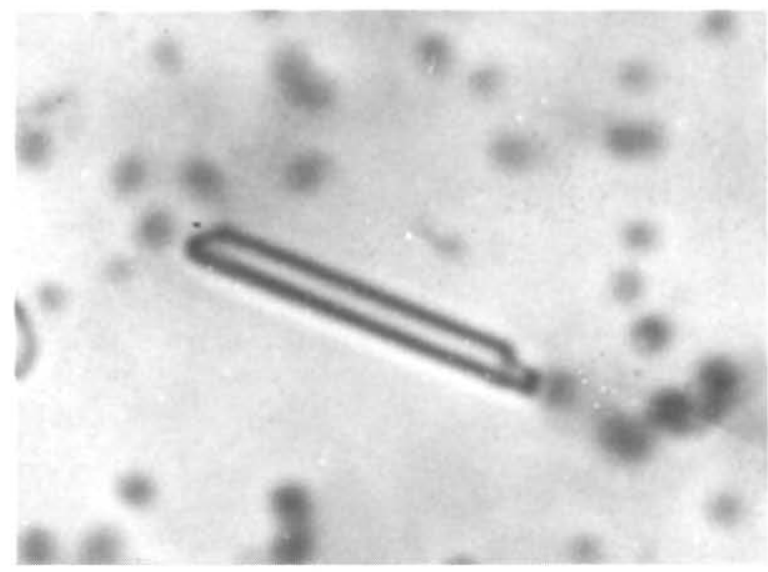

Fig. 6. Prismatic rutile. Object 12; station 2111, $3199 \mathrm{~m}$. (LM. Transm. Width of picture $=10 \mu \mathrm{m}$.)

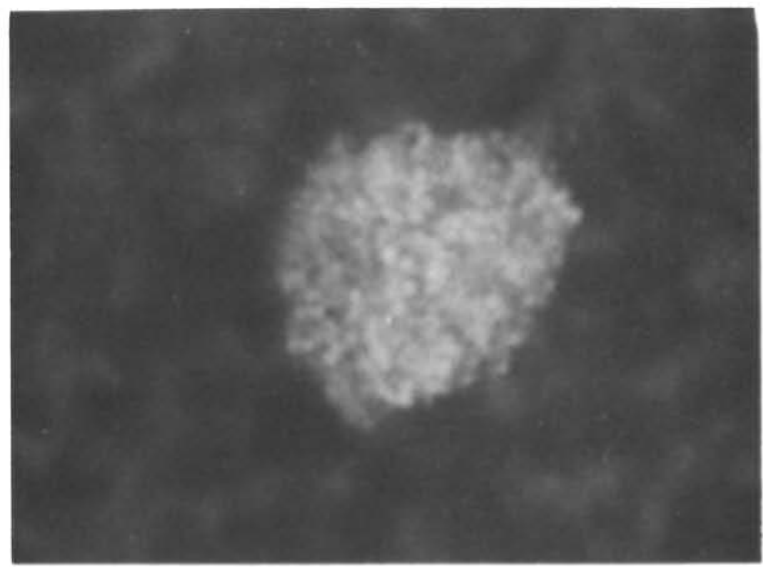

Fig. 7. Cluster of pigmentary titanium oxide. Object E23; station 2111, 2195 m. (LM. Refl. Pol. Width of picture $=20$ $\mu \mathrm{m}$.

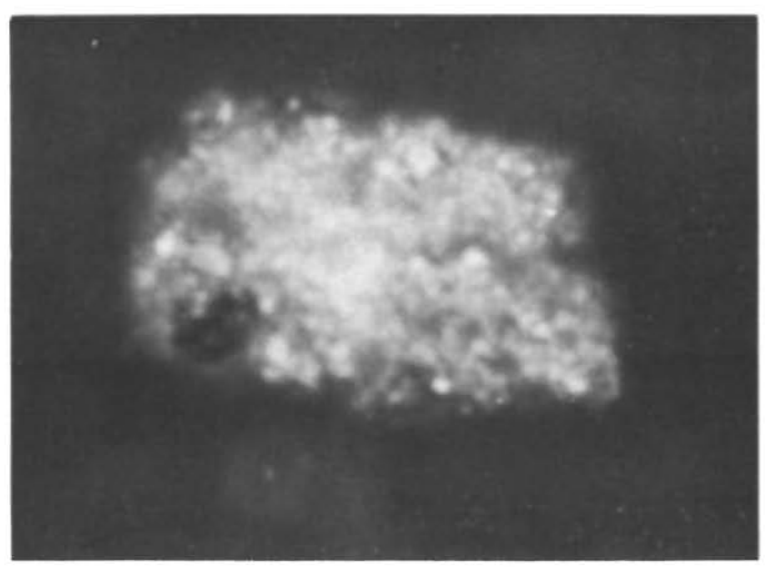

Fig. 8. Cluster of pigmentary chromium oxide. Object A15; station 2111, $2195 \mathrm{~m}$. (LM. Refl. Pol. Width of picture $=20$ $\mu \mathrm{m}$.

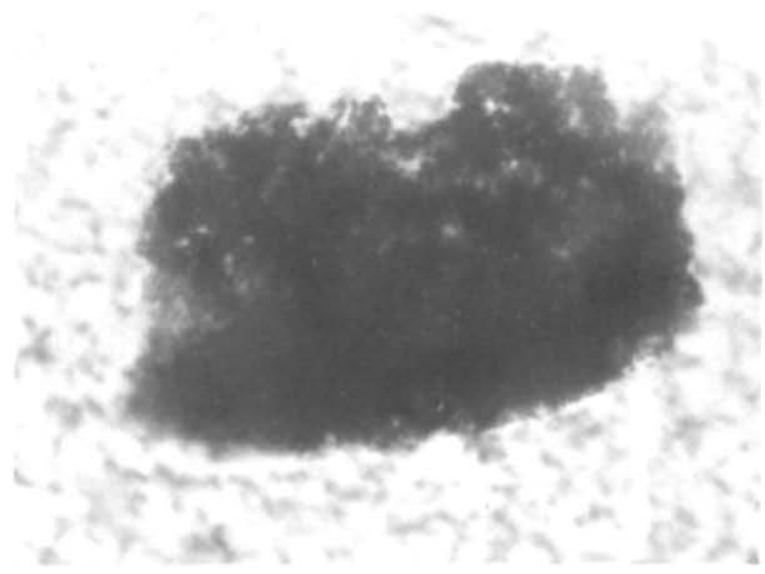

Fig. 9. Cluster of pigmentary antimony oxide, titanium oxide and iron oxide. Object 22; station 120, $2586 \mathrm{~m}$. (LM. Transm. Width of picture $=40 \mu \mathrm{m}$.) 


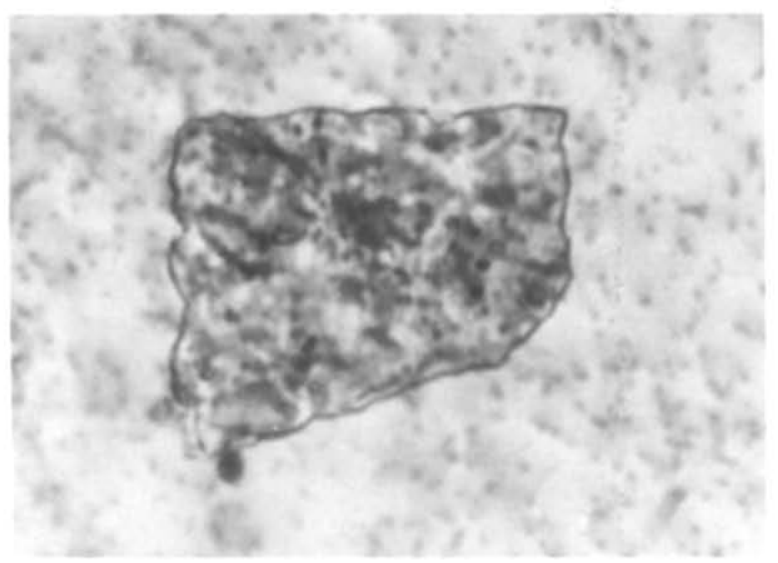

Fig. 10. Broken platelet of goethite. Object C28; station $2111,2195 \mathrm{~m}$. (LM. Transm. Width of picture $=40 \mu \mathrm{m}$.)

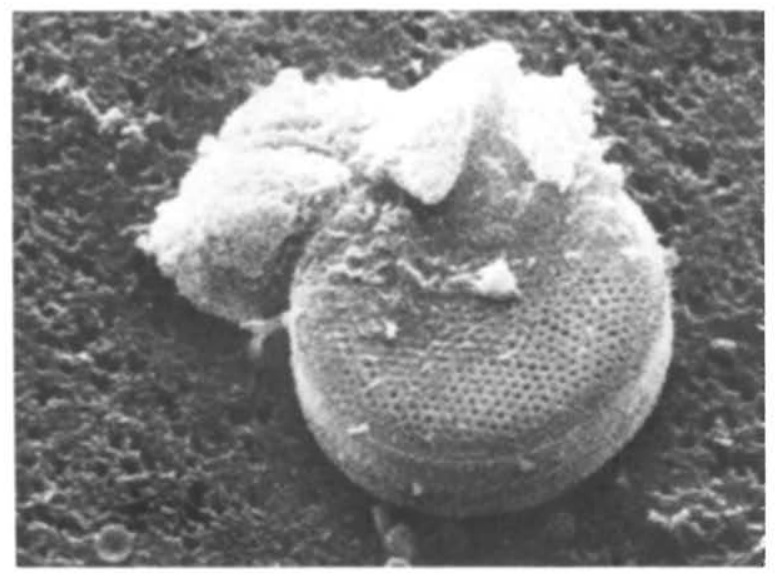

Fig. 11. Malachite deposited on a diatom. Object 1: station $120,2586 \mathrm{~m}$. (SEM. Sec. mode. Width of picture $=44 \mu \mathrm{m}$.)

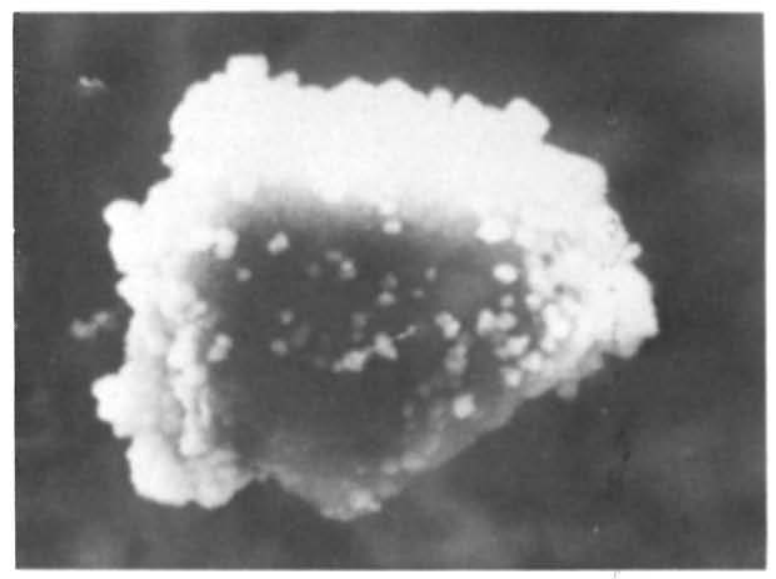

Fig. 12. Laurionite deposited on a silica fragment, Object 71 ; station $31,4701 \mathrm{~m}$. (SEM. Sec. mode. Width of picture $=22$ $\mu \mathrm{m}$.

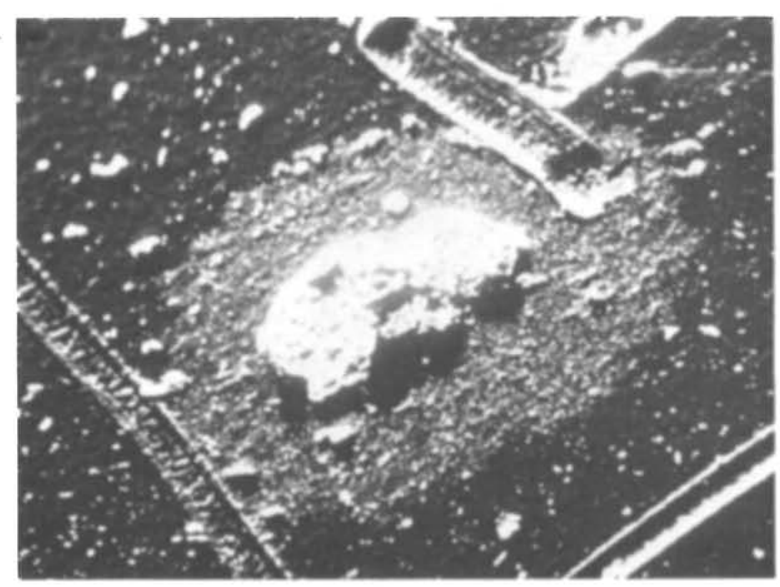

Fig. 13. Flake of zinc hydroxychloride. The bright halo around the central crystallized flake is also enriched in zinc and chlorine. Object 141; station 31, $4701 \mathrm{~m}$. (SEM. Reflect. mode. Width of picture $=800 \mu \mathrm{m}$.)

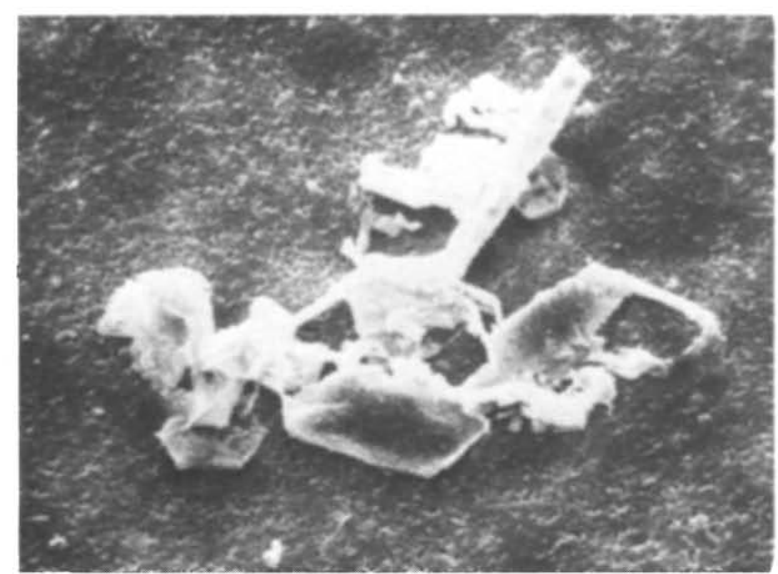

Fig. 14. Group of decayed zinc hydroxychloride crystals. Object 142; station 31, $4701 \mathrm{~m}$. (SEM. Sec. mode. Width of picture $=126 \mu \mathrm{m}$.)

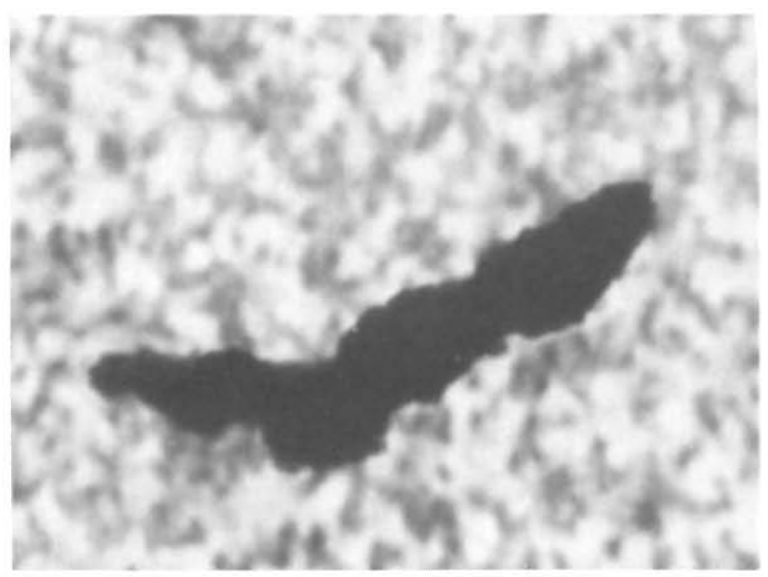

Fig. 15. Black sausage. Object 8; station 120, $2586 \mathrm{~m}$. (LM. Transm. Width of picture $=40 \mu \mathrm{m}$.) 


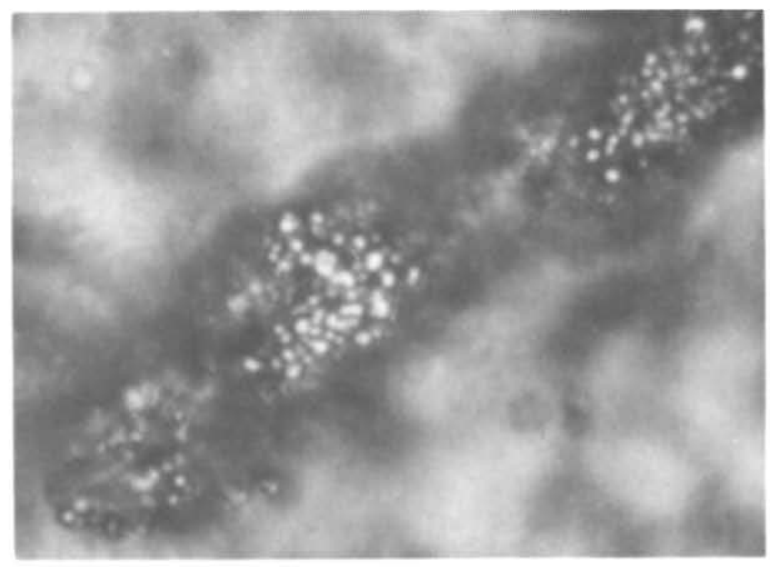

Fig. 16. Black sausage. Enlargement of Fig. 15. (LM. Refl. Width of picture $=20 \mu \mathrm{m}$.)

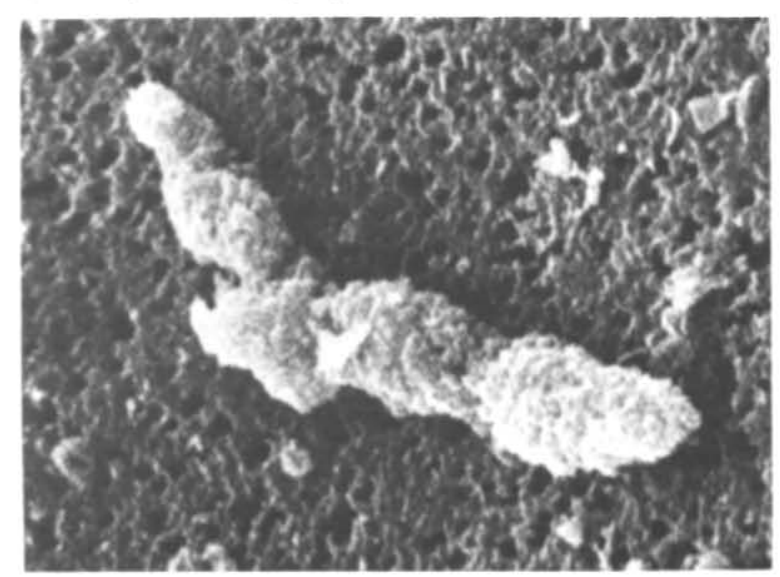

Fig. 17. Black sausage. Same object as in Fig. 15. (SEM. Sec. mode. Width of picture $=34 \mu \mathrm{m}$.)

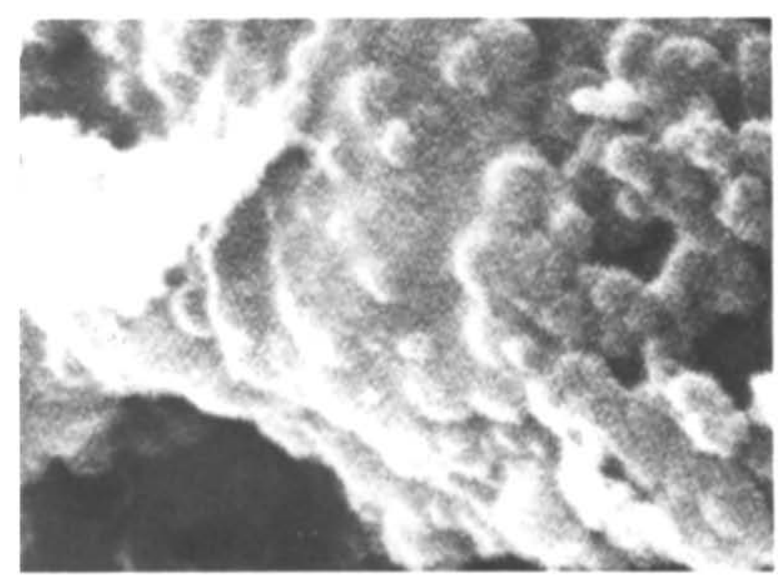

Fig. 18. Black sausage. Enlargement of Fig. 17. (SEM. Sec. mode. Width of picture $=8 \mu \mathrm{m}$.)

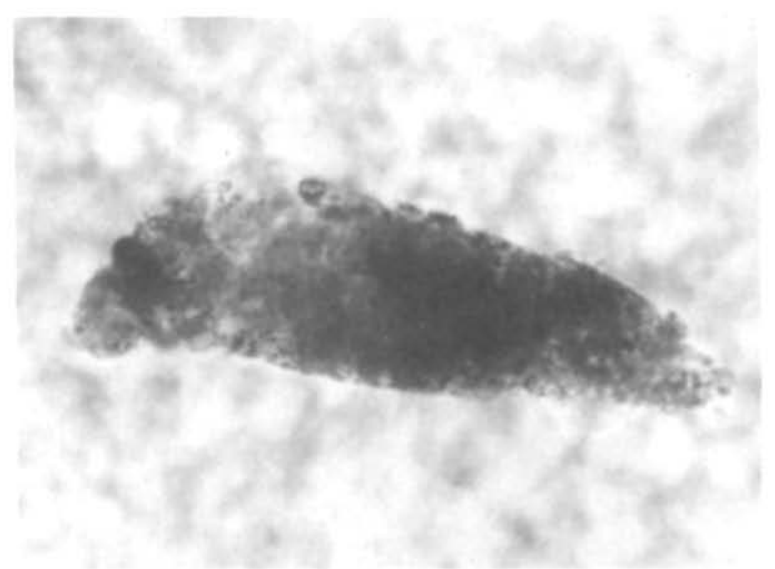

Fig. 19. White sausage. Object 23; station 120, 2586 m. (LM. Transm. Width of picture $=80 \mu \mathrm{m}$.)

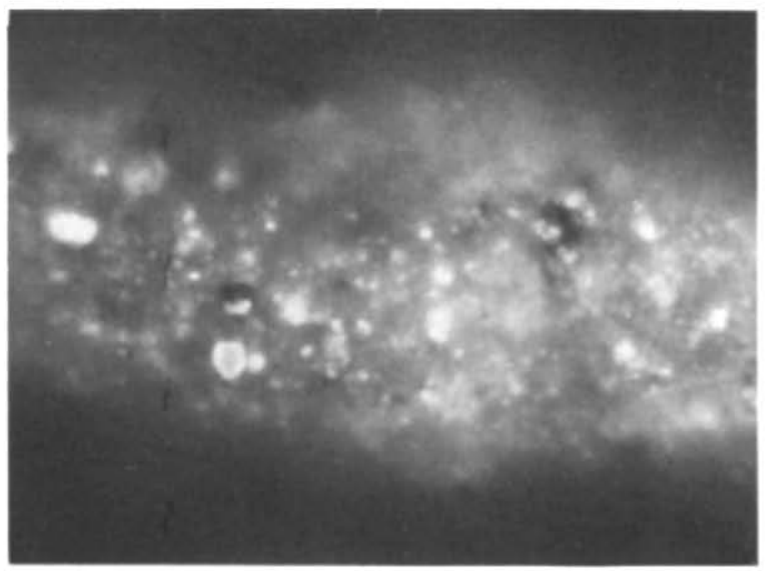

Fig. 20. White sausage. Enlargement of Fig. 19, showing numerous inclusions of goethite, titanium oxide and black opaque particles. (LM. Refl. Pol. Width of picture $=32 \mu \mathrm{m}$.)

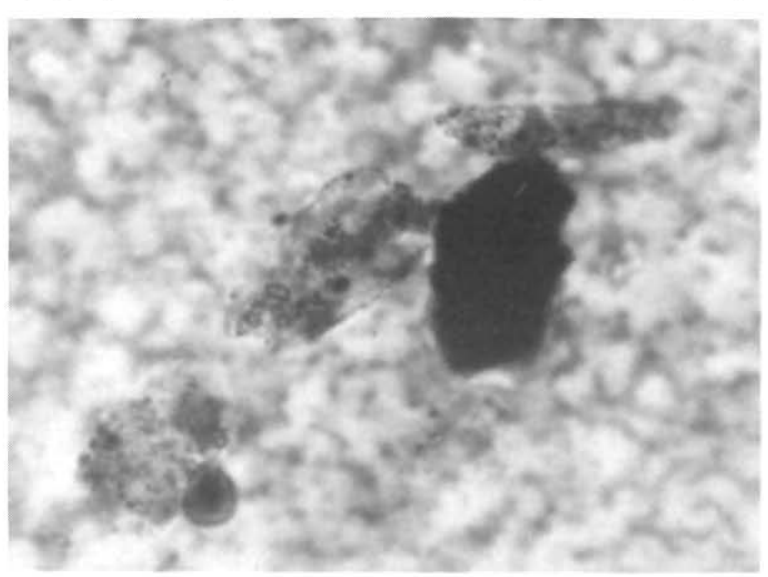

Fig. 21. Three white sausages, one black sausage and one brown sphere. White sausages: transparent with small inclusions. Black sausage: opaque black. Brown sphere: rounded small body at lower left. Object 20; station 120, $2586 \mathrm{~m}$. (LM. Transm. Width of picture $=58 \mu \mathrm{m}$.) 


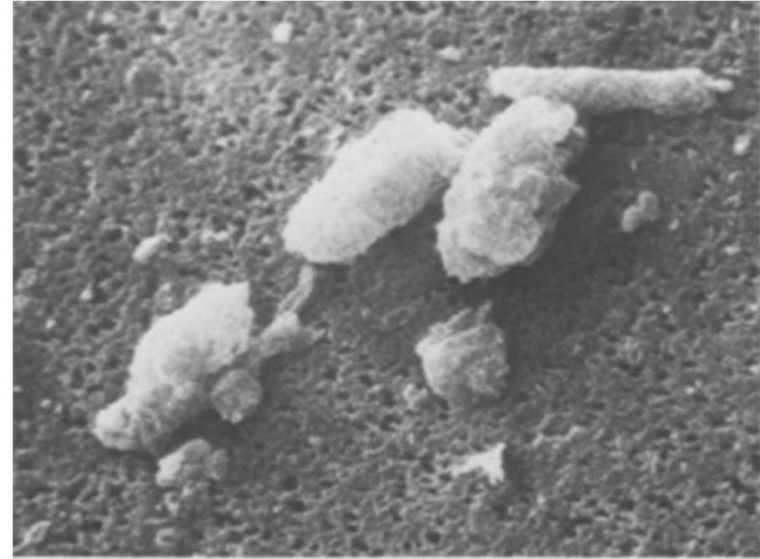

Fig. 22. Same group of particles as in Fig. 21. This picture shows the wealth of details observed under the LM, and the lack of "colour" under the SEM. (SEM. Sec. mode. Width of picture $=61 \mu \mathrm{m}$.)

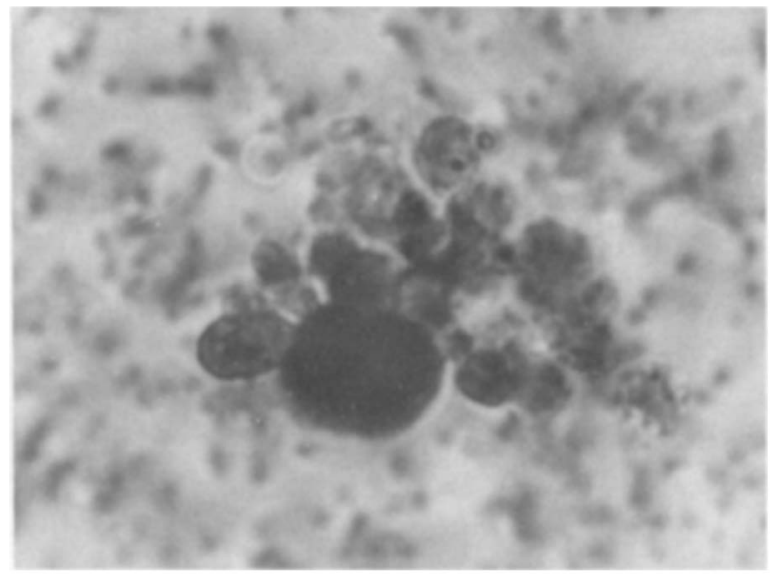

Fig. 23. Cluster of brown spheres. Object 69; station 2111, $954 \mathrm{~m}$. (LM. Transm. Wid th of picture $=42 \mu \mathrm{m}$.)

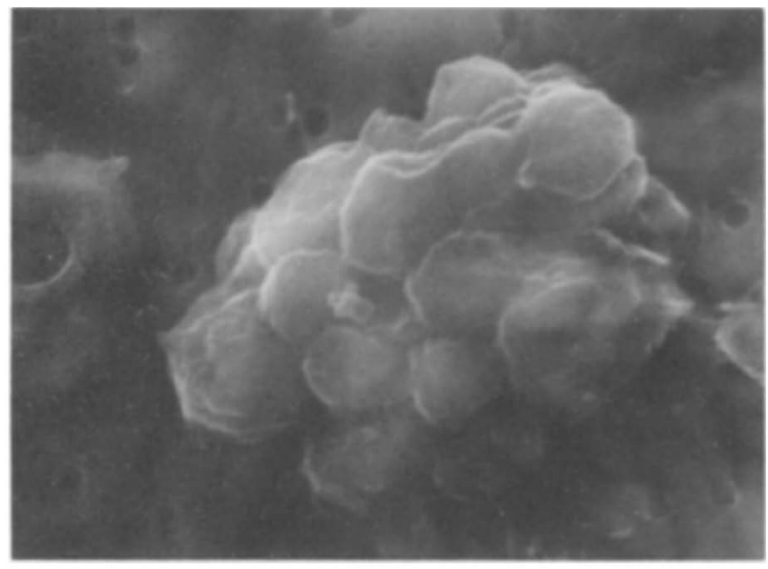

Fig. 24. Cluster of brown spheres. Object 29; station 2111 , $954 \mathrm{~m}$. (SEM. Sec. mode. Width of picture $=16 \mu \mathrm{m}$.)
Brass. The chemical composition of brass particles is highly variable, with the copper always the most important: zinc is well known to be quickly leached from brass in seawater. Tin is rarely present, but when it is, the amount may be rather high.

Hexagonal hematite. This very specific habit (Fig. 4) has been found associated with small rutile prisms (Fig. 6). It is very similar to the red pigment of Triassic salt deposits.

Copper oxides. The particles which have been extracted and X-rayed were always composite, and give reflection spots of tenorite and paratenorite. Red copper oxide (cuprite) has never been found: all red, hematite-like particles always give a pure $\mathrm{Fe}$ spectrum.

Zinc hydroxychloride. Very large, round flakes of $\mathrm{Zn}-\mathrm{Cl}$, surrounded by a rim also enriched in $\mathrm{Zn}$ and $\mathrm{Cl}$, are observed on $\mathrm{Cu}-\mathrm{Zn}-\mathrm{Pb}$-rich filters from GEOSECS station 31 in the Sargasso Sea (Fig. 13). The overall shape and the rim suggest a pasty state at the time of the filtration. Lewin and Alexander [25] made interesting comments on the absence of natural minerals corresponding to the various zinc hydroxychlorides which are observed on altering brass. These zinc hydroxychlorides are supposed to transform readily into the more stable carbonate, which we have also found. The corroded crystals of Fig. 14 are probably the intermediates between the altered brass and the final zinc mineral(s).

Coenospheres and "black sausages". These objects are very similar to the carbonaceous particles found in urban atmosphere, but the specific trace elements of the latter $(\mathrm{S}, \mathrm{Cl}, \mathrm{V}, \mathrm{Fe}, \mathrm{Ni}, \mathrm{Pb}, \mathrm{Br})$ are not always present. This could indicate either a leaching of these elements, or various origins.

Brown spheres. Similar spheres have been observed by Fournier [32] but his had a yellow-green colour. His observation of opaque inclusions has also been repeated. He attributed these spheres to algae (chrysophyta), but they are also very similar to the proteinoid microspheres synthesized by Hsu and Fox (see pictures in Francis et al. [33]). 
White sausages. The morphology and composition are reminiscent of fecal pellets, but the producing animals could not be identified. They regularly contain noticeable amounts of zinc in their matrix. As large particles, they ought to fall rapidly through the water column, and as they are sometimes very abundant and contain numerous allogenous particles, they represent a potentially large flux of material [24].

\section{Discussion}

The number of rare particle species suspended in deep ocean waters is rather limited and does not exceed forty or so. Considering the number of filters studied and their geographic and bathymetric distribution, it can be estimated that the number of undiscovered species cannot exceed another 40 or 50 . This result is rather interesting, since it means that in such an immense domain with so many different sources of particles, very active processes are at work to limit the number of micron-size, optically emerging species.

\subsection{Origin of particles}

A tentative classification of the observed particles is presented in Table 2, according to their presumed origin. This classification is based on our current knowledge of human and natural processes, and is proposed as a set of reasonable assumptions.

The two main possible sources of particles which have been considered are the following:

Anthropogenic sources: sources of particles with unique chemical and/or morphological properties, produced purposefully or as by-products by man, and eventually injected in the oceans without severe transformations.

Natural sources: products of wind and river abrasion of continental rocks, aerial and submarine vulcanism, abrasion and alteration of submarine rocks, precipitation of insoluble compounds, complete transformation of artifacts with complete obliteration of the initial state, biological activities, meteorite ablation.

According to this classification, some particle species are exclusively and "evidently" anthropogenic, since no natural homologue is known (Group I).
Others are exclusively and "evidently" natural, since they are plentiful, or useless, or impossible to synthesize (Group II). But several particle species withstand a two-way classification, and three more groups must be defined.

Group III: Particles which are produced by nature in such restricted amounts, compared to man's output, that an anthropogenic main source is very likely, but difficult to prove definitively. An example is the case of metallic copper which is found rarely in basaltic and serpentinitic rocks [10].

Group IV: A large group of particles produced by man's activities, but also by some of the natural processes mentioned before. The case of the black, magnetic spherules is well documented: they are produced by arc welding and cutting of iron, by meteorite ablation and by volcanoes [19]. Such particles can of course not be used as anthropogenic tracers, and must be classified in a special group. But further studies of secondary properties will perhaps lead to more specific attributions, and narrow the width of this group.

An important family in this group are the $\mathrm{Cu}-\mathrm{Zn}$ $\mathrm{Pb}$ minerals [7]. There is no doubt that a large part of them result from the alteration of artifacts [25], since numerous particles composed of a brass nucleus, altered along their rim to tenorite, malachite or atacamite, are found at metal-rich GEOSECS stations (stations 17,31 and 115). Laurionite and cerussite are also associated with the $\mathrm{Cu}-\mathrm{Zn}$ minerals at the same stations as isolated crystals or as mechanical and chemical mixtures with copper minerals. But it would of course be hardly justifiable, with the available data, to consider all these minerals as entirely anthropogenic: incrustation phenomena of marine objects have been observed, which prove that the heavy metals are mobile in ocean water, to some extent. But it remains that their discovery deserves now a serious effort to assess the importance of the various sources.

A quite similar case is that of the iron oxides, and especially the yellow-brown goethite-like particles, which are sometimes very abundant. They contain a host of minor elements, and it is tempting to assign the goethites containing $\mathrm{Cr}, \mathrm{Ni}, \mathrm{Mn}, \mathrm{Cu}, \mathrm{Zn}$ and $\mathrm{Pb}$ to formerly metallic artifacts. But the data are very scanty, mainly because partially altered iron flakes are missing. It is also probable that some of the goethites have grown in more than one stage. 
TABLE 2

Origin of rare particles in deep ocean waters

Group I: Exclusively anthropogenic particles

stainless steel

brass

aluminum

polycrystalline rutile

cobalt aluminate

iron vanadium carbide

"black sausages" (with V, Ni, Br, Pb)

zinc hydroxychloride

Group II: Exclusively natural particles

sulfur

iron sulfide

sphalerite

covellite

hexagonal hematite

ilmenite

prismatic rutile

mesitine

bastnaesite

celestite

pyroxene and amphibole

coal

Group III: Presumably anthropogenic particles

iron

copper chromium oxide(eskolaite)

antimony oxide(valentinite)

ultramarine(Lazurite)

Group IV: Anthropogenic and natural particles

hematite (fragments and spheres)

magnetite

goethite

(para)tenorite

malachite

malachite-rosasite

(hydro)cerussite

smithsonite-hydrozincite

(par-)atacamite

laurionite

barite

glass spheres

coenospheres

"black sausages" (without V, Ni, Br, Pb)

Group V: Particles of unknown origin

iron zinc silicate

brown spheres

"white sausages"
Group V: This very restricted group contains the particle species which could not be classified in one of the foregoing groups. Brown spheres and "white sausages" belong probably to the natural species, but are ranked in this interim group until their more definite attribution. The iron-zinc silicate is extremely rare, and is presented as an example of the fully unexpected compounds which we could probably encounter in the future.

\subsection{Quantitative aspects}

A few words should be said about the frequency of occurrences and the amounts of rare particles present on the filters, although these aspects have not especially been pursued in this descriptive work.

It should first be remembered that 4-10 liters of water were filtered on 37- or 47-mm-diameter Nuclepore filters of about $0.5 \mu \mathrm{m}$ pore size. The visual scan of a whole filter shows at most a few hundred rare particles with equivalent diameters ranging from 2 to $20 \mu \mathrm{m}$. Assuming a maximum of 1000 rare particles of average density of $2.6 \mathrm{~g} / \mathrm{cm}^{3}$ and a lognormal distribution, one calculates then a weight at about 0.5 $\mu \mathrm{g}$, and a range of concentrations of $0.1-0.05 \mu \mathrm{g} / 1$. As the weight of total particulate matter has been found by Brewer et al. [3] to be between 5 and 300 $\mu \mathrm{g} / \mathrm{l}$, this gives extreme weight percentages for the rare particles of $0.017-2.4 \%$. On some filters from GEOSECS station 31 , which is very remarkable for its heavy metal minerals, the concentration of malachitelike species amounts to $1 \%$ of the total particulate matter.

The most frequently occurring species are in 
decreasing order: goethite-“white sausages"-_."black sausages"-polycrystalline rutile-brown spheres. It should be said that "specialized filters" occur, i.e. filters on which large amounts of one of these four species are immediately recognizable. Filters from the North Atlantic sometimes bear large amounts of all the most frequent types of rare particles.

\section{Conclusions}

Although the concentrations of the investigated particles are very low in seawater and in total particulate matter, it has been found that the sampling methods, the volumes of water and the amounts of collected particles, and the experimental methods were adequate to begin a study of their distribution and origins.

A group of definitely anthropogenic particle species has been found. Some are easily recognizable and probably very stable in the oceans, i.e., the inorganic pigments. They could give long-range indications about anthropogenic inputs to the oceans, since the dates of beginning of massive production are rather well known for each pigmentary species [34].

Other species which are also certainly anthropogenic are less stable, like the metals and alloys, or very unstable, like zinc hydroxychloride, and evolve into more stable, specific heavy metal minerals. These intermediate reaction products should help in the understanding of the fate of heavy metals in seawater.

Remnants of fossil fuel combustion are also present, and in particular, automobile soot particles which still show the presence of some of the original trace elements $(\mathrm{V}, \mathrm{Ni})$ and of the additives $(\mathrm{Pb}, \mathrm{Br})$.

Several compounds, which are never synthesized by man and which were considered as natural, even if they were mobilized by man, were also found, indicating inputs to the oceans from various sources which are generally difficult to ascribe.

A large group of particle species, among which the most interesting are the heavy metal minerals $(\mathrm{Cu}$, $\mathrm{Zn}, \mathrm{Fe}, \mathrm{Pb}$ ) cannot yet be fully attributed, since they may have various anthropogenic and natural origins. But it has also been proved that at least a part of these species may be attributed to primary inputs of man-made metals.

\section{Acknowledgements}

This work has been made possible by support from the NSF-IDOE Program, the CNRS (France) and several people among whom it is our pleasure to acknowledge P. Biscaye, R. Chesselet, E.D. Goldberg and K.K. Turekian.

\section{References}

1 H. Craig and K.K. Turekian, The GEOSECS program 1973-1976, Earth Planet. Sci. Lett. 32 (1976) 217.

2 National Academy of Sciences and National Academy of Engineering, The International Decade of Ocean Exploration: An Oceanic Quest (NAS-NSF, Washington, D.C., 1969).

3 P.G. Brewer, D.W. Spencer, P.E. Biscaye, A. Hanley, P.L. Sachs, C.L. Smith, S. Kadar and J. Fredericks, The distribution of particulate matter in the Atlantic Ocean, Earth Planet. Sci. Lett. 32 (1976) 389.

4 W.C. McCrone and J.G. Delly, The Particle Atlas (Ann Arbor Science Publ., Ann Arbor, Mich., 1973) 2nd ed., 4 volumes.

5 J. Jedwab, A method of extraction and analysis of possible cosmic particles from manganese nodules, Meteoritics 10 (1975) 233.

6 Belgian Patent No. 830.067 (1975).

7 J. Jedwab, Copper, zinc and lead minerals suspended in ocean waters, Geochim. Cosmochim. Acta 43 (1979) 101.

8 F. Dehairs, R. Chesselet and J. Jedwab, Discrete suspended particles of barite and the barium cycle in the open ocean, Earth Planet. Sci. Lett. 49 (1980) 528 (this issue).

9 Joint Committee on Powder Diffraction Standards, Selected Powder Diffraction Data for Minerals (JCPDS, Swarthmore, Pa., 1974) 2 volumes.

10 P. Ramdohr, The Ore Minerals and Their Intergrowths (Pergamon, Oxford, 1969).

11 W. Uytenbogaardt and E.A.J. Burke, Tables for Microscopic Identification of Ore Minerals (Elsevier, Amsterdam, 1971).

12 T.C. Patton, Pigment Handbook (John Wiley and Sons, New York, N.Y., 1973) 3 volumes.

13 C. Palache, H. Berman and C. Frondel, The System of Mineralogy (John Wiley and Sons, New York, N.Y., 1944-1951) 3 volumes.

14 R.E. Stoiber and W.I. Rose, Fumarole incrustations at active Central American volcanoes, Geochim. Cosmochim. Acta 38 (1974) 495.

15 D.T. Rickard, The microbiological formation of iron sulfides, Stockholm Contrib. Geol. 20 (1969) 49.

16 J. Honnorez, B. Honnorez-Guerstein, J. Valette and A. Wauschkuhn, Present day formation of an exhalative sul- 
fide deposit at Vulcano (Thyrrhenian Sea), II. Active crystallization of fumarolic sulfides in the volcanic sediments of the Baia di Levante Ores in sediments, In: Ores in Sediments, G.C. Amstutz and A.J. Bernard, eds. (Springer, Berlin, 1973) 139.

17 D.T. Rickard, Covellite formation in low temperature aqueous solutions, Mineral. Deposita 1 (1972) 180.

18 E.T. Degens and D.A. Ross, Hot brines and recent heavy metal deposits in the Red Sea (Springer, Berlin, 1969).

19 R.A. Schmidt, A survey of data on microscopic extraterrestrial particles, revised June 1964, NASA TN-D2719 (1964).

20 D.W. Folger, Wind transport of land-derived mineral, biogenic and industrial matter over the Atlantic, Deep-Sea Res. 17 (1970) 337.

21 M.G. Ross, Geologic aspects of waste solids and marine waste deposits, New York metropolitan region, Geol. Soc. Am. Bull. 83 (1972) 3163.

22 F.T. Manheim and R.H. Meade, Suspended matter in surface waters of the Atlantic continental margin from Cape Cod to the Florida Keys, Science 167 (1970) 371.

23 D.S. Cronan, Authigenic minerals in deep-sea sediments, in: The Sea, 5. Marine Chemistry, E.D. Goldberg, ed. (John Wiley and Sons, New York, N.Y. 1974).

24 J.K.B. Bishop, J.M. Edmond, D.R. Ketten, M.P. Bacon and W.B. Silker, The chemistry, biology and vertical flux of particulate matter from the upper $400 \mathrm{~m}$ of the equatorial Atlantic Ocean, Deep-Sea Res. 24 (1977) 511.

25 S.Z. Lewin and S.M. Alexander, The composition and structure of natural patinas, Part I: Copper and copper alloys, section B: 1930 to 1967 ; Part II: Zinc and zinc alloys, 1872 to 1969 ; Part III: Tin, lead and their alloys,
1873 to 1964 ; Suppl. Art Archeol. Tech. Abstr. 7 (1968) 279(I); 151 (II); 173 (III).

26 W.H. Berger and U. von Rad, Cretaceous and Cenozoic sediments from the Atlantic Ocean, in: D.E. Hayes et al., Initial Reports of the Deep-Sea Drilling Project, XIV (U.S. Government Printing Office, Washington, D.C., 1972).

27 G. Bianchi and P. Longhi, Copper in sea water; potentialpH diagrams, Corros. Sci. 13 (1973) 853.

28 D.T. Richard and J.O. Nriagu, Aqueous environmental chemistry of lead, in: The Biochemistry of Lead in the Environment, Part A. Ecological Cycles, J.O. Nriagu, ed. (Elsevier, Amsterdam, 1978).

29 W.A. Deer, R.A. Howie and J. Zussman, Rock-Forming Minerals (Longmans, Green and Co., London, 1963) 5 volumes.

30 P.E. Biscaye, Mineralogy and sedimentation of recent deep-sea clay in the Atlantic Ocean and adjacent seas and oceans, Geol. Soc. Am. Bull. 76 (1965) 803.

31 J.J. Griffin and E.D. Goldberg, The fluxes of elemental carbon in coastal marine sediments, Limnol. Oceanogr. 20 (1975) 456.

32 R.O. Fournier, North Atlantic deep-sea fertility, Science 153 (1966) 1250

33 S. Francis, L. Margulis and E.S. Barghoorn, On the experimental silicification of microorganisms, II. On the time of appearance of eukaryotic organisms in the fossil record, Precambrian Res. 6 (1978) 65.

34 J. Jedwab and R. Chesselet, Paint pigments: an overlooked group of stable technological tracers, in: Biogeochemistry of Estuarine Sediments (UNESCO, Paris, 1978). 